\section{Attitude of the first year medical students towards medicine as career: Motivations and apprehensions of being a doctor}

\author{
Saurabh Sharma, ${ }^{1}$ Pawan Parashar, ${ }^{2}$ \\ Chandra Mohan, ${ }^{3}$ Alka Singh, ${ }^{2}$ \\ Sartaj Ahmad ${ }^{4}$
}

${ }^{1}$ Medical Education Unit; ${ }^{2}$ Department of Community Medicine, Subharti Medical College, Meerut; ${ }^{3}$ Department of Cardiology, Himalayan Institute of Cardiology, Dehradun; ${ }^{4}$ Medical Sociology, Department of Community Medicine, Subharti Medical College, Meerut, India

\begin{abstract}
The choice of a career as a doctor is a complex personal decision influenced by a multitude of factors. These include family background, role models, media, and personal experiences. The present study was done with the objectives to know the reasons for first-year medical students for joining MBBS and their apprehensions. A cross-sectional study carried out among first-year students of batch 2018, 2019, and 2020 of a Medical College of North India. The data was collected within 10 days of admission in MBBS. A total of 278 students were given pre-designed and pre-validated questionnaire after informed consent. Out of multiple reasons for being doctor respect in society was the largest, i.e. $83 \%$, while $72 \%$ joined because of high earning by the doctor. More than $80 \%$ had a professional image of the doctor as a calm, helping and well-groomed person, while $60 \%$ thought doctors don't listen properly, and $57 \%$ had a perception that doctors are not much concerned about the problems of patient. Sixtyeight percent $(68 \%)$ thought media doesn't portray a good image of doctors. According to students outrage in the community and lack of trust for doctors were the major reasons for violence against doctors. Munnabhai MBBS, Anand and Patch Adams, Sanjeevani and House MD were the movies and series motivated most students to be a doctor. Respect in society was the prime motivator to be a doctor among students still they feel media doesn't justify the image of doctors. Movies and television series can be used to keep the students high in morale and excitement.
\end{abstract}

\section{Introduction}

There are more than 76928 MBBS (Bachelor of Medicine and Bachelor of Surgery) seats in 532 Medical Colleges in India for pursuing the MBBS course. This is not enough as India is yet to achieve the World Health Organization (WHO) recommended the doctor-patient ratio. Medicine is still not the first choice for students of this era. The perspective of the students and the rationale for choosing a particular career are of great importance for councilors around the world. ${ }^{1-2}$

The students have many career options and thus they may feel confused what to choose. The decision process may involve many aspects like personal interest, peer pressure, self-motivation, financial reasons etc. $^{3}$

A career in medicine is unique as it is believed to be very virtuous providing a chance to serve humanity more than any other career. ${ }^{4}$ Many factors affect the choice of medicine as career and career choices are influenced both by the graduate's inclination before starting medical school as well as any exposure during training in medical school. ${ }^{5-6}$ These include gender and residency conditions e.g. part-time work and parental leave availability, family background, parent's socioeconomic status, prestige, income and role models, controllable lifestyle versus non controllable lifestyle, local market forces committed relationship and the of employment availability. ${ }^{7-12}$

The final choice results from an integrated interplay between external and internal factors of the prime motivation of medical students by asking students about the personal reasons for being a doctor. ${ }^{13}$

A reflective analysis of doctor s' reasons for entering medicine found five main factors being good in science stream, ambition of being a doctor, wanting a good interesting career, influenced by friends and relations, and desire to serve community. ${ }^{14}$

Sometimes possible motivations fall into conflict. Serving people and doing scientific research are both admirable motivations, but very often both activities cannot be carried out at the same time requiring a decision as to which is the more important for a particular doctor. ${ }^{15}$

Considering all these aspects the present study has been undertaken with the objectives to assess the reasons for joining MBBS. Students were also questioned about the image of a doctor in mind developed because of their personal experience and media before joining medical school because by this we will come to know by what mindset they entered medical school
Correspondence: Alka Singh, Department of Community Medicine, Subharti Medical College, Subhartipuram, NH-58, DelhiHaridwar, Meerut Bypass Rd, Meerut, Uttar Pradesh 250005, Meerut, India. E-mail: alkasingh24593@gmail.com

Key words: Medical students; attitude; career; motivation; media and movies.

Acknowledgements: The Authors acknowledge the respondents who had truly given their views and participated openly regarding questions asked by them on different aspects of choosing the career.

Contributions: SS, PP, AS: research idea, design, data collection, data analysis, manuscript writing; CM: research idea, design, data collection, manuscript writing; SA: research idea, design, data analysis, manuscript writing.

Conflict of interest: The authors declare no conflict of interest.

Availability of data and materials: All data generated or analyzed during this study are included in this published article.

Ethics approval and consent to participate: The Ethics Committee of INSTITUTION approved this study (SMC/IEC/2018/189). The study is conformed with the Helsinki Declaration of 1964, as revised in 2013, concerning human and animal rights. All participants in this study signed a written informed consent form for participating in this study.

Informed consent: Written informed consent was obtained from a legally authorized representative(s) for anonymized patient information to be published in this article.

Received for publication: 27 February 2021. Revision received: 19 November 2021

Accepted for publication: 19 November 2021.

This work is licensed under a Creative Commons Attribution 4.0 License (by-nc 4.0).

${ }^{\circ}$ Copyright: the Author(s), 2021

Licensee PAGEPress, Italy

Healthcare in Low-resource Settings 2021; 9:9710 doi:10.4081/hls.2021.9710

and can work to correct the same.

\section{Materials and Methods}

The present study was a cross-sectional study and it has been carried out among first-year students of a Medical College of Swami Vivekanand Subharti University, situated in Northern part of India. A total of 278 students were given a pre-designed and 
pre-validated questionnaire. The questionnaire was designed after reviewing previously published content about the similar topic ${ }^{5-12}$ and after a thorough discussion among the research team members. The face validity of questionnaire was done by distributing the questionnaire to senior medical faculty after explaining them the intent of the study. They were then asked to evaluate whether the questions effectively capture the topic under investigation and whether the questionnaire was free of confusing or leading questions. Later a pilot study was done on 30 medical students other than those who would have been participating in the study, and retrospective approach with verbal probes were used to test and validate it. The questionnaire included gender, age, presence of doctors in the family and the questions regarding reasons for choosing a medical school, professional image of doctors they have in mind influenced by their personal experience and media. The questionnaire had multiplechoice (multiple options allowed) and openended questions. The study was done from April 2018 to Feb 2021.All the 278 students (88 students in 2018, 83 students in 2019, and 107 in 2020) present on the day of data collection were given questionnaire and everyone responded. Informed consent was taken from the students. Data entry and analysis were done by using Microsoft excel and the chi-square test of association was used.

\section{Results}

The present study was conducted among 278 students in the first year of college. Among them, $65 \%$ and $35 \%$ were males and females respectively. In the study, only $28.9 \%$ of students have at least one member of the family who is a doctor and lives in the same household. Table 1 shows the reasons for the choice of medicine as a career among students. Table 2 shows the professional image of doctors among students by their personal experiences in interactions with doctors. Figure 1 shows the view of students regarding the media putting the correct image of doctors in public. Figure 2 shows the causes of violence against doctors as perceived by stu- dents. Table 3 shows the list of movies/series, which most inspired the students to be a doctor. There was no statistical

MEDIA PORTRAY GOOD IMAGE OF DOCTORS

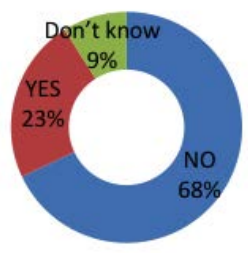

Figure 1. Students views media portraying good image of doctors.

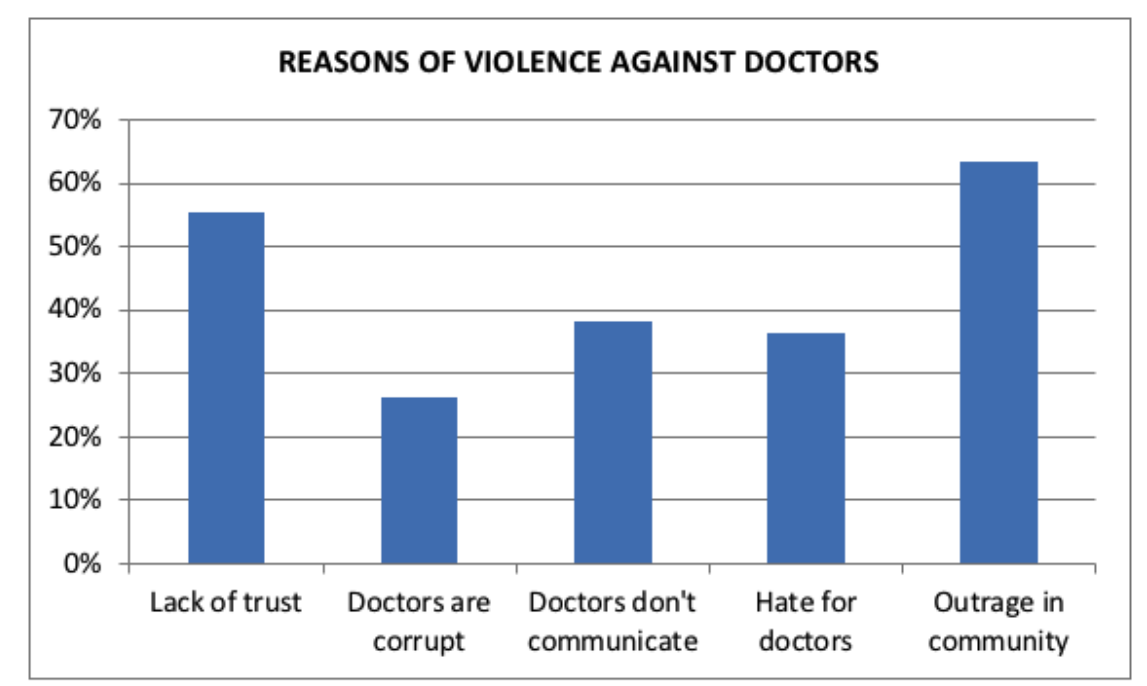

Figure 2. According to students reasons of violence against doctors.

Table 1. Reasons behind the choice of medicine as career among students $(\mathrm{N}=\mathbf{2 7 8})$.

\begin{tabular}{lcc} 
Reasons (multiple options chosen) & Percentage (\%) & Frequency \\
Passion for this profession & 47 & 130 \\
Respect in society & 83 & 230 \\
\hline Parents' choice & 41 & 114 \\
Monetary benefits & 72 & 200 \\
\hline Others & 7 & 19 \\
\hline
\end{tabular}

Table 2. Professional image of doctors among students ( $n=278)$.

\begin{tabular}{lcccc}
\hline Professional Image & Positive & Number (\%) & Negative & Number (\%) \\
Behavior & Calm & 85 & Arrogant & 15 \\
Nature & Helping & 80 & Non helping & 20 \\
\hline Dressing & Well dressed & 68 & Clumsily dressed & 32 \\
Grooming & Well Groomed & 90 & Badly Groomed & 10 \\
\hline Communicator & Soft spoken & 66 & Harsh & 34 \\
Listener & Patient Listener & 40 & Non Listener & 60 \\
\hline Empathy & Pacifier & 43 & Not Concerned & 57
\end{tabular}

Table 3. Movies/series which inspired students most to be a doctor.

\begin{tabular}{ll} 
Sr no & Name of the Movies/ TV Serials \\
1 & Munabhai MBBS \\
\hline 2 & Anand \\
\hline 3 & Patch Adams \\
4 & Awakenings \\
\hline 5 & Contagion \\
\hline 6 & Sanjeevani (series) \\
\hline 7 & Kabirsingh \\
8 & Bhoolbhulaiya \\
\hline 9 & House MD \\
10 & Sherlock Holmes \\
\hline 11 & The Good Doctor \\
12 & Kahaan hum kahaan tum (series) \\
\hline 13 & Savitridevi college and hospital \\
14 & Kyonki its fate
\end{tabular}


difference observed among students of 2018, 2019, and 2020 batch regarding their attitude and motivation towards being a doctor $(\chi 2-2.5, p-0.27)$. When both the genders were compared regarding their attitude and motivation towards being a doctor the difference was not found to be statistically significant $\left(\chi^{2}-7.9, \mathrm{p}-0.094\right)$

\section{Discussion}

Medical education in India is regulated by National Medical Commission (NMC). As per NMC guidelines, undergraduate medical education includes 4.5 years of college and 1 year of compulsory rotatory internship. The first year is of premedical subjects while from the second year onwards there are clinical rotations in the wards along with theory lectures. Undergraduate students are assessed by term exams and final university exams for 4 phases, which includes both theory and practical exam. Practical exams happen after every clinical rotation. In 2019 NMC launched AETCOM (Attitude, Ethics and Communication Module) and Foundation course to enhance the prospect of human dignity and welfare in medical education. Post-graduation (MD/MS) lasts three years. The study was done on first-year undergraduate medical students in the first month of joining the course as by this time these students are not influenced by the environment in Medical College and express the perceptions and views close to those of a layman non-medical person.

Twenty-eight percent (28.9\%) of students had medical background and they have seen the life of doctors in their family, so their views may not match with that of the students who were first doctors in their family.

Eighty-three percent $(83 \%)$ of the students have chosen medicine because they have seen very high respect for doctors in society. This finding matches with a systemic review by Sonu Goel et al. ${ }^{16}$ where it was observed that the main reason in uppermiddle-income countries was respect for themselves and social and professional status. Forty-seven percent (47\%) of the students joined because they love the profession the result is close to $61 \%$ which was observed in the study done by Seetharaman and Logaraj ${ }^{17}$ in South India. Self-interest was found to be the main reason for $82.6 \%$ of the students in a study done by Jothula. ${ }^{18}$

In a systemic review by Sonu Goel et $a l .{ }^{16}$ interest in science and medicine was the reason for joining medical studies in most of the high-income countries. Fortyone percent $(41 \%)$ of the students in our study chose this profession because of the pressure by parents and they were not interested in the stream, while in their studies Seetharaman and Logaraj ${ }^{17}$ and Jothula ${ }^{18}$ found parental wish or pressure to be $53 \%$ and $26.6 \%$ respectively; $72 \%$ in our study sought monetary benefits for choosing a profession in comparison of $44 \%$ and $54 \%$ of Jothula ${ }^{18}$ and Seetharaman and Logaraj ${ }^{17}$ respectively.

Usually in childhood or young age, a person gets inspired to be in a profession by observing someone successful in that profession or a role model. In our study, we asked for the professional image of the doctor to get an idea of the mindset with which they are joining the medical school. In our study behavior, nature, dressing, grooming, communication, and empathy were considered and results show most of the students had a positive professional image of doctors except for two aspects (being a good listener and empathy). Only $40 \%$ of students have seen a doctor being good listener and $43 \%$ felt they have empathy. Empathy to students was described as an intellectual quality that permits an understanding of the experience, concerns, and perspectives of a patient, as well as the skill to communicate that understanding. The students should be taught about the importance of empathy to be a successful doctor. ${ }^{19}$

Discussion about empathy among students regularly becomes more important after it was found in multiple researches that clinical empathy level declines while getting more experienced and older. ${ }^{20-24}$

Media these days play a big role in shaping the thought process of a person so the image of doctors shown in media may affect the decision of a student to pick medicine as a career. Sixty-eight percent $(68 \%)$ of students were of the opinion that media portray a bad image of doctors and most of the things in media create a bad image of doctors. In their opinion, this has an impact on a lack of trust among patients and doctors and thus could be one of the reasons for violence against doctors. In an article, Gupta $^{25}$ expressed that in India an important factor responsible for assault against doctors is the unpleasant image of medical professionals projected by the media, leading to the general belief that doctors exploit patient's distress to mint money. Violence against doctors has been reported from all over the world, with negative media reports about hospitals and doctors, out-of-pocket medical expenditures by the patients, and lack of trust in doctors and hospitals have been reported to be some of the causative factors. ${ }^{26-27}$

Fictional diseases and treatments are rare to occur, but when extraordinary themes are repeated many times they become routine in the general person's view. So people come to expect either wonder or tragedy, whereas, in reality, both are unusual. ${ }^{28}$ The disparity between fictional and actual medical accounts can influence patients' perceptions of physicians' ability to find a solution. News about violence for the people of profession students aspires to be in for whole life creates fear among students and $63 \%$ of students had the perception that every doctor has to go through these types of incidences at least once in their professional life.

According to the view of students while media generally play a bad plot for doctors there are some movies and television series, which creates a very good image of doctors and inspired the students to be a doctor. Some of these are Munnabhai MBBS, Anand, Sanjeevani (series), Kabirsingh, Bhoolbhulaiya, House MD, Sherlock Holmes, The good doctor, Kahaan hum kahaan tum (series), Savitri Devi college and hospital, Kyonki its fate, Patch ADAMS, Awakenings, Contagion, etc. This aspect can be used further to educate medical students on various aspects of humanity and profession. Movies are increasingly being used to educate students about many of the essential values of the medical profession. ${ }^{29}$ Movies may address various consequences of disease such as suffering, emotions, social conflicts, and ethical dilemmas. ${ }^{30}$ Movies have been used as teaching-learning aids in diverse subjects/areas such as microbiology, pharmacology, medical ethics, doctor-patient relationship, clinical research, mental illness, and professionalism among others. ${ }^{31}$

\section{Conclusions}

Students enter medical school with high enthusiasm and expect to have a good reputation in society as doctors. In medical school, movies can be used as a tool to create empathy among students and to develop a sense of pride in their profession.

\section{References}

1. Pruthi S, Pandey R, Singh S, et al. Why does an undergraduate student choose medicine as a career. National Med J India 2013;26:147-9.

2. Barber S, Brettell R, Perera-Salazar R, et al. UK medical students' attitudes towards their future careers and general practice: a cross-sectional survey and qualitative analysis of an Oxford cohort. BMC Med Educ 2018;18:160. 
3. Sharma D, Pattnaik S. Carrier choices and the factors influencing it among medical students in a private medical college in Tamilnadu. Int J Community Med Public Health 2017;4:1110-2

4. Woodward A, Thomas S, Jalloh MB, et al. Reasons to pursue a career in medicine: a qualitative study in Sierra Leone. Glob Health Res Policy 2017:2:34.

5. Ie K, Murata A, Tahara M, et al. What determines medical students' career preference for general practice residency training? A multicenter survey in Japan. Asia Pac Fam Med 2018:17:2.

6. Yang Y, Li J, Wu X, et al. Factors influencing subspecialty choice among medical students: a systematic review and meta-analysis. BMJ Open 2019;9: e022097.

7. Marchand C, Peckham S. Addressing the crisis of GP recruitment and retention: a systematic review. $\mathrm{Br} \mathrm{J}$ Gen Pract 2017;67:e227-37.

8. Kunanitthaworn N, Wongpakaran $\mathrm{T}$, Wongpakaran N, et al. Factors associated with motivation in medical education: A path analysis. BMC Med Educ 2018;18:140.

9. Guraya SY, Almaramhy HH. Mapping the factors that influence the career specialty preferences by the undergraduate medical students. Saudi J Biol Sci 2018:25:1096-101.

10. Pfarrwaller E, Audétat MC, Sommer J, et al. An expanded conceptual framework of medical students' primary care career choice. Acad Med 2017;92:153642.

11. Woolley T, Larkins S, Sen Gupta T. Career choices of the first seven cohorts of JCU MBBS graduates: producing generalists for regional, rural and remote northern Australia. Rural Remote Health 2019;19:4438.

12. Alavi M, Ho T, Stisher C, et al. Factors that influence student choice in family medicine: A national focus group. Fam Med 2019;51:143-8.

13. Moir F, Yielder J, Sanson J, Chen Y. Depression in medical students: current insights. Adv Med Educ Pract 2018;9:323-33.

14. Cleland JA, Johnston P, Watson V, et al. What do UK medical students value most in their careers? A discrete choice experiment. Med Educ 2017;51:839-51.

15. Martin AJ, Beska BJ, Wood G, et al. Widening interest, widening participation: Factors influencing school students' aspirations to study medicine. BMC Med Educ 2018;18:117.

16. Goel S, Angeli F, Dhirar N, et al. What motivates medical students to select medical studies: a systematic literature review. BMC Med Educ 2018;18:16.

17. Seetharaman N, Logaraj M. Why become a doctor? Exploring the career aspirations and apprehensions among interns in South India. Nat J Res Com Med 2012;1:178-241

18. Jothula KY, Ganapa P, Sreeharshika D, et al. Study to find out reasons for opting medical profession and regret after joining MBBS course among first year students of a medical college in Telangana. Int $\mathrm{J}$ Community Med Public Health 2018;5:1392-6.

19. Haque M. Importance of empathy among medical doctors to ensure highquality healthcare level. Adv Hum Biol 2019;9:104-7

20. Igde FA, Sahin MK. Changes in empathy during medical education: An example from Turkey. Pakistan J Med Sci 2017;33:1177-81.

21. Hojat M, Shannon SC, DeSantis J, et al. Does empathy decline in the clinical phase of medical education? A nationwide, multi-institutional, cross-sectional study of students at DO-Granting Medical Schools. Acad Med
2020;95:911-8.

22. Piumatti G, Abbiati M, Baroffio A. et al. Empathy trajectories throughout medical school: relationships with personality and motives for studying medicine. Adv in Health Sci Educ 2020;25:122742.

23. Nair S, Shetty RS, Guha S, et al. Assessing empathy among undergraduate medical students: a cross sectional analysis using the Jefferson scale in a medical school in Coastal Karnataka. Int J Community Med Public Health 2018;5:953-95.

24. Tariq N, Rasheed T, Tavakol M. A quantitative study of empathy in Pakistani medical students: A multicentered approach. J Primary Care Community Health 2017:8:294-299.

25. Gupta VK. Is changing curriculum sufficient to curb violence against doctors? Indian Heart J 2016;68:231-41.

26. Sen M, Honavar SG. It's a doc's life Workplace violence against doctors. Indian J Ophthalmol 2019;67:981-4.

27. Reddy IR, Ukrani J, Indla V, Ukrani V. Violence against doctors: A viral epidemic? Indian J Psychiat 2019;61:7825.

28. Bitter CC, Patel N, Hinyard L. Depiction of resuscitation on medical dramas: Proposed effect on patient expectations. Cureus 2021;13:e14419.

29. Ortiz MB. Commercial cinema as a learning tool in medical education, from potential medical students to seniors. AMEE Med Ed Publish 2018;7:17.

30. Shankar PR. Cinemeducation: Facilitating educational sessions for medical students using the power of movies. Arch Med Health Sci 2019;7:96-103.

31. Kadeangadi DM, Mudigunda SS. Cinemeducation: Using films to teach medical students. J Sci Soc 2019;46:73-4 